Basrah Journal Of Surgery
Original Article

Bas J Surg, June, 25, 2019

\title{
LOCAL EXPERIENCE OF TOTAL KNEE REPLACEMENT IN BASRAH
}

\section{Thamer A Hamdan ${ }^{@}$, Khalil I Sadek ${ }^{\#}$ \& Mohammed AbedYasir ${ }^{*}$}

${ }^{\circledR}$ FRCS, FICS, FACS, FRCP, American Board of Neurological \& Orthopedic Surgery, Professor of Orthopedic Surgery. ${ }^{\#}$ FICMS, Orthopedic specialist, Basrah Teaching Hospital. ${ }^{*}$ CABHS Orthopedic specialist, Al-Sadr Teaching Hospital, Basrah, IRAQ.

\begin{abstract}
Total knee arthroplasty (TKA) represents a major advance in the treatment of degenerative joint disease providing excellent restoration of joint function and pain relief.

This is a prospective study undertaken in the Department of Orthopedic Surgery in Basrah Teaching Hospital, from October 2009 to June 2011. Thirty-three patients who underwent primary total knee arthroplasty were included (25 females $75.7 \%$ and 8 males 24.2\%). The diagnosis was osteoarthritis in 20 knees and rheumatoid arthritis in 13 knees. The operation included primary cemented TKA (25 cruciate-retaining and 8 cruciate-substituting), by anterior approach. The knee function was evaluated by knee society score system.

Preoperative functional knee scores were uniformly poor and improved postoperatively with excellent results in 18 knees (54.54\%), good in 9 knees (27.27\%), fair in 5 knees (15.15\%), and poor in 1 knee (3\%). Thus, excellent and good results were achieved in $81.8 \%$ of the cases (27 of 33 knees). For knee scores, 2 knees (6\%) were fair preoperatively and another 31 knees (93.9\%) were poor. Post TKA results were excellent in 28 knees (84.84\%), good in 5 knees (15.15\%), fair in (0\%) and poor in $(0 \%)$. Excellent and good results were achieved in $100 \%$ of cases. The most common complications were superficial infection and deep venous thrombosis

In conclusion, this study showed good outcome for total knee replacement surgery in our region. Excellent relief of pain, range of motion, and restoration of function.

Keywords: Total Knee Replacement, Osteoarthritis, Rheumatoid arthritis, Basrah, Surgery.
\end{abstract}

\section{Introduction}

7 otal knee replacement is used to treat approximately 35000 patients with knee osteoarthritis (OA) in the UK each year ${ }^{1}$. The procedure is performed primarily to reduce pain associated with the degenerative disease and to restore a degree of normal knee function ${ }^{2,3}$. The beneficial implications of a return towards normal function include better mobility and an improved functional effect on other lower limb joints by removing the need for compensatory gait mechanisms. Total knee arthroplasty is becoming increasingly popular due to improvements in technology and durability of implants and has become a standard and dependable method of treating severe knee arthritis ${ }^{4-8}$.

\section{Patients and Methods}

This prospective study was carried out to evaluate the outcome of primary TKA performed in the Department of Orthopedic Surgery in Basrah Teaching Hospital, from October 2009 to June 2011. Thirty-three patients (25 females and 8 males) were included. Their age ranged from 32-76 years with a mean age 
of 52.7. Patients have osteoarthritis in 20 knees and rheumatoid arthritis in 13 knees. Seventeen in the right side and sixteen in the left side.

Primary cemented TKAs (25 cruciateretaining, 8 cruciate-substituting) were performed by the same orthopedic surgeon.

All patients were evaluated by detailed history, thorough physical examination of knee (instability, deformity, and range of motion), laboratory investigation and imaging studies that included $\mathrm{x}$-ray (weight bearing antero-posterior, lateral and skyline view as shown in figure 1 .

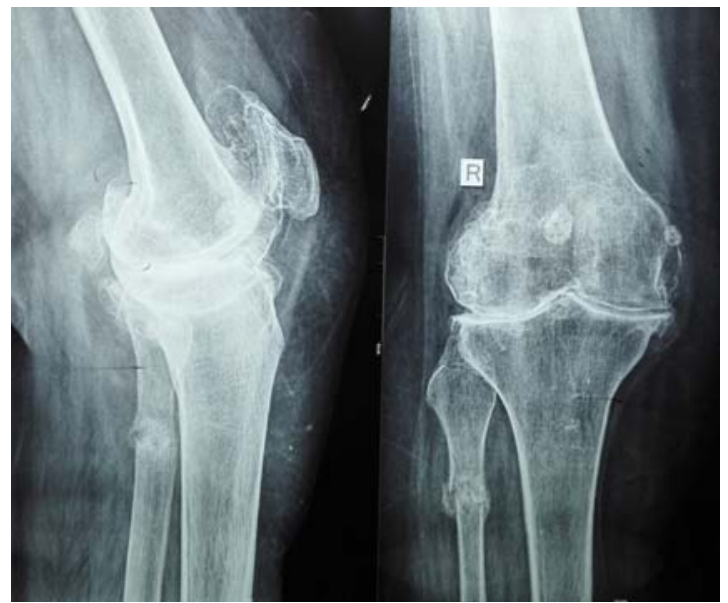

Figure 1:Pre-operative x-ray of knee joint

Preoperative preparation includes: stabilization of patients general condition, which included control of co-morbid medical illnesses. Pre-operative informative discussion was made with all patients about the technique, it's functional outcome, and possible complications. All patients received physical therapy before operation.

Intraoperative: Prophylactic antibiotic (ceftriaxone 1g.) was given intravenously at induction of anesthesia. Thirty surgeries were done under general anesthesia and three surgeries under spinal anesthesia.

Surgical approach was; midline incision $(12-15 \mathrm{~cm}) \quad$ length with medial parapatellar arthrotomy. In some cases synovectomy was done. The bone cut was done according to preoperative templating and was followed by achieving the ligamentous balance. A was drain used in all cases and was removed within 48 hours. Duration of the surgery ranged from 75 minute to 120 minute.

Postoperative management included prophylactic antithrombotic with enoxaparine iv (4000 iu per day) for 5 days and then warfarin tab. $5 \mathrm{mg}$ for 10 days then aspirin $100 \mathrm{mg}$ for 3 months postoperativel.

A compressive dressing and ice was applied to the knee to relieve pain and to decrease postoperative hemorrhage for the first 24 hours.

An x-ray was done postoperatively as shown in figure 2 .

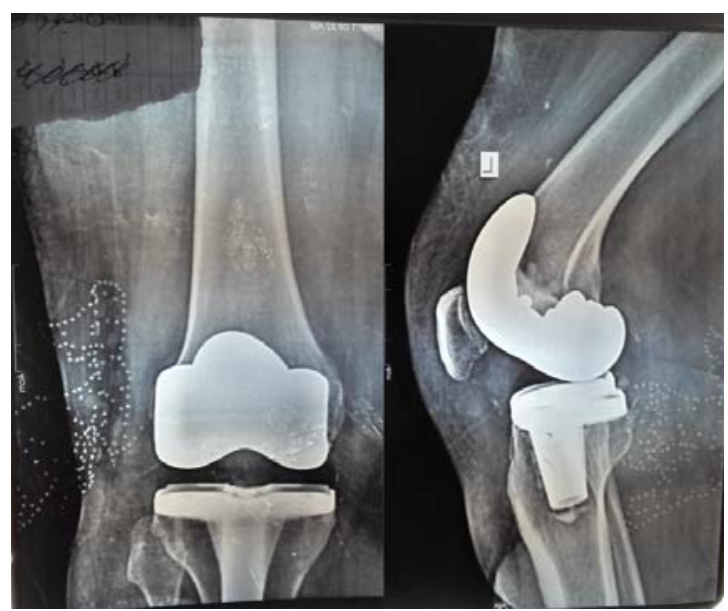

Figure 2: post total knee replacement

In all patients, physiotherapy was started in day one after operation including; static quadriceps muscle, active straight leg raising and mobilizing with crutches. Weight bearing mobilization with walker was started on the 2nd day. Discharge was mostly five days after operation Follow up: Sutures removed 2 weeks after operation and then monthly follow up, all patients were evaluated by Knee Society Score which is divided into knee score and knee functional score ${ }^{9}$.

\section{Results}

Thirty three patients underwent primary cemented TKA, their age ranged from 32 
to 76 years with a mean of $52.7 \%$. They were mostly presented between ages of 40-59 years (about 63.6\%) as shown in table I.

Table I:Age distribution of the patients

\begin{tabular}{|l|l|l|}
\hline Age / years & Number & Percentage \\
\hline $30-39$ & 4 & 12.13 \\
\hline $40-49$ & 9 & 27.27 \\
\hline $50-59$ & 12 & 36.36 \\
\hline $60-69$ & 5 & 15.15 \\
\hline$>70$ & 3 & 9.09 \\
\hline Total & 33 & $100 \%$ \\
\hline
\end{tabular}

The operation was conducted on females (25 patients, 75.75\%) more than males (8 patients, 24.25\%)

The pathological process mostly encountered in the study was osteoarthritis $60.6 \%$.

Most of surgeries were done on the right side (17 patients, $51.5 \%$ ), while on the left side were done for 16 patients (48.5\%).

Pain, a significant component of the knee score, improved significantly after TKA. Preoperative pain score was 13.03 points while postoperative pain score was 45.15 points.

Range of motion was improved significantly, The mean pre-operative range of flexion of the knee was $73^{\circ}$, while the mean post-operative range of flexion was $104^{\circ}$

The mean Knee scores and functional scores were improved significantly as shown in table II.

\section{Table II: Mean scores}

\begin{tabular}{|l|l|l|}
\hline $\begin{array}{l}\text { Knee society } \\
\text { score }\end{array}$ & Preop. & Postop. \\
\hline $\begin{array}{l}\text { Mean knee } \\
\text { score }\end{array}$ & $\begin{array}{l}42.69 \\
\text { points }\end{array}$ & $\begin{array}{l}91.6 \\
\text { points }\end{array}$ \\
\hline $\begin{array}{l}\text { Mean functional } \\
\text { score }\end{array}$ & $\begin{array}{l}30.6 \\
\text { points }\end{array}$ & $\begin{array}{l}80.45 \\
\text { points }\end{array}$ \\
\hline
\end{tabular}

Preoperative functional knee scores were uniformly poor and improved postoperatively with excellent results in 18 knees (54.54\%), good in 9 knees (27.27\%), fair 5 knees (15.15\%), and poor in 1 knees (3\%). Thus, excellent and good results were achieved in $81.8 \%$ of the cases (27 of 33 knees).

For knee scores; 2 knees (6\%) were fair preoperatively and 31 knees (93.9\%) were poor. Post TKA results were excellent in 28 knees (84.84\%), good in 5 knees $(15.15 \%)$, fair in $(0 \%)$ and poor in (0\%). Excellent and good results were achieved in $100 \%$ of the cases as shown in table III.

Table III: Grading of clinical results in 33 patient using Knee Society Score system

\begin{tabular}{|l|l|l|l|l|l|l|}
\hline Result & $\begin{array}{l}\text { Functional } \\
\text { Score }\end{array}$ & $\begin{array}{l}\text { No. of } \\
\text { knees }\end{array}$ & Percentage & Knee score & $\begin{array}{l}\text { No. of } \\
\text { Knees }\end{array}$ & Percentage \\
\hline Excellent & $80-100$ & 18 & $54.54 \%$ & $85-100$ & 28 & $84.85 \%$ \\
\hline Good & $70-79$ & 9 & $27.27 \%$ & $70-79$ & 5 & $15.15 \%$ \\
\hline Fair & $60-69$ & 5 & $15.15 \%$ & $60-69$ & 0 & $0 \%$ \\
\hline Poor & $<60$ & 1 & $3.03 \%$ & $<60$ & 0 & $0 \%$ \\
\hline
\end{tabular}

Mean walking score preoperatively was 12.42 points, and improved postoperatively to 38.18 points.

The capability to climb stairs also improved significantly after TKA.

Preoperatively, the mean stair climbing scores were 18.84 point and improved postoperatively to 42.42 points. The need to use a cane or walking sticks to assist walking also improved following surgery. Knee score and functional score had improved to a greater degree more in rheumatoid arthritis than in osteoarthritis as shown in table IV. 
Table IV: A comparison of knee society scores between OA and RA

\begin{tabular}{|l|l|l|}
\hline American Knee Society Scores & Osteoarthritis & Rheumatoid \\
\hline Knee Score & 89.85 & 94.3 \\
\hline Functional Score & 76.75 & 86.15 \\
\hline
\end{tabular}

The most common complications in our patients were superficial infection and deep venous thrombosis as shown in table V. Superficial wound infection was noted in 2 TKAs, and both responded well to intravenous antibiotics (vancomycin and ceftriaxone for 3 weeks). Deep venous thrombosis noted in 2 TKAs and they were treated successfully with antithrombotic.

Table V: Complications

\begin{tabular}{|l|l|l|}
\hline Complications & Number of knees & Percentage \\
\hline Delay wound healing & 1 & $3 \%$ \\
\hline Superficial infection & 2 & $6 \%$ \\
\hline Deep venous thrombosis & 2 & $6 \%$ \\
\hline Instability & 1 & $3 \%$ \\
\hline Total & 6 & $18 \%$ \\
\hline
\end{tabular}

\section{Discussion}

This study was carried out to evaluate the outcome of the first TKA experience In Basrah. The majority of patients underwent TKA in the present study were females $(75.7 \%)$ and the preoperative diagnosis was osteoarthritis in 20 knees (60.6\%) and rheumatoid arthritis in 13 knees (39.3\%). This is similar to reported results by Dhillon et al. where the majority of their patients were females (76\%) and preoperative diagnosis was osteoarthritis in $81 \%$ of the cases ${ }^{10}$. Schai et al. reported $62 \%$ of their patients had knee osteoarthritis and 33\% with rheumatoid arthritis ${ }^{11}$.

Ranawat et al. reported that most of their patients were females (80\%) and osteoarthritis was present in $44.6 \%$ of their sample while rheumatoid arthritis was noted in $53.4 \%$ of cases ${ }^{12}$.

The mean age in this study was 52.7 years (range, 32-76y) which was lower than the mean age of other studies in the seven decade of life: (Stern and Insall, an average age was 63 years (range, 17 to $87 y$ ); Scott et al. an average age of 66.9 years (range 22 to $85 \mathrm{y}$ ); and Schurman et al. average age of 63.5 years ${ }^{13-15}$. This can be explained by difference in age incidence of mortality rate for Iraqi people, on the other hand, younger average ages were reported by: Duffy et al. age was 43 years; Diduch et al. average age of 51 years (range 22 to 55 years); on other hand in 8th decade, Ewald et al. average age of 76 years ${ }^{16-18}$. Dhillonet al. reported an average age of 66.5 years (range 21 to 85 years) ${ }^{10}$.

Regarding the range of motion, there was improvement postoperatively with the mean 104 ( ranged from 90-115), these results goes with Ranawat et al. and Duffy et al. with mean post operative range of motion in their studies 99, 100 degrees respectively.

Overall, the knee scores and functional scores significantly improved after TKA. In this study, $100 \%$ of knee scores were either excellent or good, an outcome that is similar to other studies. For instance, the following reported good or excellent results: Ewald et al. 90\% (111 knees); Diduch et al. 100\% (103 knees); Ranawat et al. 92\% (103knees); Scott et al. reported 98\% (116 knees) ${ }^{13,17,19,20}$.

Mean postoperative knee score was high (41.6) which is in agreement with Duffy et al. who reported significant 
improvement of knee score postoperatively (preoperative knee score of 36 points compared to 84 points postoperatively ${ }^{16}$.

Pain improved in $98 \%$ of TKAs. Callahanet al. noted good and excellent outcome varied from $52 \%$ to $100 \%$ amounts in the meta-analysis of 57 studies $^{21}$.

Functional scores also showed significant improvement after TKA. The mean preoperative score was 30.6 while the mean post TKA functional score mean was 80.45. Similarly, Duffy reported similar significant improvement from mean preoperative functional mean score of 45 points to a postoperative mean of 60 points ${ }^{16}$.

The functional score was excellent, good and fair in 96.9\% (32 knees) and poor results in 1 knee (3\%). Dhillon et al. reported 50\% (50 knees) had poor results and another $50 \%$ good and fair results ${ }^{10}$.

In the present study, the incidence of deep infection was $0 \%$, superficial infection $6.06 \%$, instability $3.03 \%$, and DVT 6.06. There were no instances periprosthetic fracture, pulmonary embolism, neurovascular or peroneal nerve injury.

Callahan et al. reported that approximately $18 \%$ of patients experienced postoperative complications following TKA. These included: superficial infections 3.9\% (range, $0 \%$ to $14.8 \%$ ); deep infections $1.7 \%$ (range, $0 \%$ to $11.4 \%$ ), pulmonary embolism $2 \%$ (range, 0\% to 9.7\%), DVT 6.5\% (range, $0 \%$ to $56.6 \%$ ), peripheral nerve injury $2.1 \%$ (range, $0 \%$ to $18.8 \%)^{21}$. Scott et al. reported $13.1 \%$ complications post TKA including deep infections delayed healing (3 knees), death, urinary tract infection (2 each), hepatitis (1 knee) and patella fracture (6 knees).

Diduch et al. reported: late infection, $2 \%$ (2 of 103 knees); polyethylene thinning, $1 \%$, dislocation of tibial component $3 \%$, instability requiring change of the tibial insert 1\% (17). Stern and Insall reported $14(7.7 \%)$ of 180 knees needed revision for various reasons ${ }^{14}$.

Conclusion; Osteoarthritis is the main indication for TKA in our locality. Most of our patients were females and the main presenting symptom was pain. TKA is good and reproducible operation for management of our patients with both osteoarthritis and rheumatoid arthritis. The most common complications in our patients were DVT and superficial infection. Most of patients had improvement in the quality of life after TKR. 


\section{References}

1- Moran, C. G. and Horton, T. C. Total knee replacement: the joint of the decade. Br. Med. J., 2000, 320, 820.

2- Andriacchi, T. P. Functional analysis of pre and post-knee surgery: total knee arthroplasty and ACL reconstruction. Trans. ASME, J. Biomech. Engng, 1993, 115, 575-581.

3- Myles, C. M., Rowe, P. J., Walker, C. R. C., and Nutton, R. W. Knee joint functional range of movement prior to and following total knee arthroplasty measured using flexible electrogoniometry. Gait Posture, 2002, 16, 46-54.

4- Rand JA, Ilstrup DM. Survivorship analysis of total knee arthroplasty : cumulative rates of survival of 9200 total knee arthroplasties. J Bone Joint Surg Am. 1991;73:397-409.

5- Ranawat CS, Luessenhop CP, Rodriguez JA. The press-fit condylar modular total knee system : Four-to-six year results with a posterior-cruciate-substituting design. J Bone Joint Surg Am. 1997;79:342- 348.

6- Rasquinha VJ, Ranawat CS, Cervieri CL, Rodriguez JA. The press-fit condylar modular total knee system with a posterior cruciate-substituting design. A concise follow-up of a previous report. J Bone Joint Surg Am. 2006;88:1006-1010.

7- Zaki SH, Rafiq I, Kapoor A, Raut V,Gambhir AK, Porter ML. Medium term results with the press fit condylar sigma knee prosthesis.The Wrightington experience. ActaOrthop Belg. 2007;73:55-59.

8- Asif S, Choon DSK. Midterm results of cemented press fit condylar sigma total knee arthroplasty system. J of Orthop Surg. 2005:13:280-284

9- Insall JN, Dorr LD, Scott RD, Scott WN. Rationale of The Knee Society Clinical Rating System. Clin Orthop Relat Res 1989; 248: 13-4.

10- Dhillon K, Jamal, Bhupinderjeet S. Early results of Total Knee Replacement. A clinical and radiological evaluation. Med J Malaysia 1993; 48: 427-435.

11- Schai PA, Thornhill TS, Scott RD. Total Knee Arthroplasty with the PFC System. Result at a minimum of ten years and survivorship analysis. J Bone Joint Surg 1998; 80B: 850-8.

12- Ranawat CS, Flynn WF, Saddler S, Hansraj KK, Maynard MJ. Long term results of the Total Condylar Knee Arthroplasty : A15-year survivorship study. Clin Orthop Relat Res 1993; 286: 94-102.

13- Scott WN, Rubinstein M, Scuderi G : Results after knee replacement with a posterior cruciate substituting prosthesis. J Bone Joint Surg 1988; 70A: 1163-73.

14- Stern SH, Insall JN. Posterior Stabilized Prosthesis Results After follow up of nine to twelve years. J Bone and Joint Surg 1992;74A: 980-6.

15- Schurman DJ, Parker JN, Ornstein D. Total Condylar Knee Replacement : A Studyof factors Influencing range of motion as late as two years after arthroplasty. J Bone Joint Surg 1985; 67A: 1006-14.

16- Duffy GP, Trousdale RT, Stuart MJ. Total Knee Arthroplasty in patients 55 years old or younger. 10- to 17-year results. Clin Orthop Relat Res 1998; 356: 22-7.

17- Diduch DR, Insall JN, Scott N, Scuderi GR, Font-Rodriquez D. The total knee replacement in young, active patients. Long term

follow-up and functional outcome. J Bone Joint Surg 1997; 79A: 575-82.

18- Ewald FC, Jacobs MA, Miegel RE, Walker PS, Poss R, Sledge CB. Kinematic Total Knee Replacement. J Bone and Joint Surg1984; 66A: 1032-40.

19- Ranawat CS, Rodriquez JA. Malalignment and Malrotation in Total Knee Arthroplasty in Current Concepts in Primary and Revision Total Knee Arthroplasty edited by JN Insall, WN Scott and GR Scuderi Lippincott-Raven Chapter 13. 1996; 115-121

20- Diduch DR, Insall JN, Scott N, Scuderi GR, Font-Rodriquez D. The total knee replacement in young, active patients. Long term follow-up and functional outcome. J Bone Joint Surg 1997; 79A: 575-82.

21- Callahan CM, Drake BG, Heck DA, Ditlus RS. Patient outcomes following tricompartmental Total Knee Replacement. A metaanalysis.J Am Med Assoc 1994; 217(17): 1349-57. 